\title{
Das Virus, der sterbliche Mensch und Gott - vom existentiellen Sinn in der Krise zur existentiellen Sinn-Krise und zurück
}

Martin Splett

Die Corona-Pandemie hat eine weltweite Krise ausgelöst, die praktisch jeden auf die eine oder andere Weise betrifft - wenn nicht durch Infektion oder die Angst davor, dann durch vielfältige Auswirkungen von Schutzmaßnahmen; wenn nicht durch eigenes Leid, dann durch Mitgefühl mit Leidenden. Diese Krise drängt zum Nachdenken darüber, was nun praktisch zu tun ist; und das geschieht auch vielfach. Dieser philosophischtheologische Text hingegen beschäftigt sich mit der Frage, was die CoronaKrise und ihre Bekämpfung über unsere menschliche Existenz und über Gott aussagt bzw. in Erinnerung ruft ${ }^{1}$.

Für die These, dass die Beschäftigung mit Sinnfragen kein intellektuelles Glasperlenspiel ist, sei als glaubwürdiger Zeuge der jüdische Psychiater Viktor Frank $1^{2}$ angeführt: Er hat eine schlimme Zeit im Konzentrationslager überlebt, weil er ihr Sinn abgewinnen konnte. Die von ihm entwickelte Logotherapie hilft dabei, bedrohliche Situationen durch Sinngebung besser in den Griff zu bekommen. Einer Not und Krise, die man erklären kann, scheint man nicht mehr so ohnmächtig ausgeliefert zu sein. Dieser Mechanismus wirkt in verquerer Weise auch bei Verschwörungserzählungen (von Theorien sollte man hier wirklich nicht sprechen) rund um die Corona-Pandemie. Dasselbe gilt auch für das Phänomen „Schuld“: Sowohl massive Selbstvorwürfe wie die Suche nach Schuldigen bzw. Sündenböcken bieten Sinnzusammenhänge und verschaffen dadurch zunächst eine gewisse Erleichterung; doch Vorwürfe und Bestrafungen lösen langfristig keine Krise.

Des Weiteren sei vor einer zu einseitigen Rede von der „Krise als Chance" gewarnt: Natürlich soll man nach Ursachen forschen und Lehren für die Zukunft ziehen - für menschliches Zusammenleben, für den Umgang mit der Natur oder auch für Kirche und Seelsorge. Zudem begünstigt eine

1 Für wertvolle Hinweise und Anregungen danke ich Barbara Huber und Friedhelm Fuest.

2 Siehe z. B. Frankl, Der Mensch auf der Suche nach Sinn. 
optimistische Haltung ein erfolgreiches Handeln. Ohnehin hat die derzeitige Krisensituation für so Manchen auch ihre angenehmen Seiten. Doch sobald dadurch ein todbringendes Virus und seine pandemische Verbreitung zu etwas Gutem erklärt würden, wäre das zynisch und ein Hohn gegenüber den zahllosen Opfern dieser Krise, und das sind nicht nur die Kranken und die Toten! Tatsächliche oder künftig mögliche positive Auswirkungen der Corona-Pandemie rechtfertigen nicht gegenwärtiges Übel.

Darum suche ich weder einen Sinn des Corona-Virus noch den Sinn der Krise. Vielmehr frage ich vorsichtig nach Sinn in der Krise - und respektiere, wenn manche Leidende davon nichts hören wollen. Zugleich fühle ich mich zur Sinnsuche ermutigt von Leidenden, die sich nach Licht im Dunkel sehnen. Allerdings scheint die Suche nach Sinn in der Krise früher oder später auch in eine Sinnkrise zu führen; denn zur Erfahrung von Sinn gesellt sich sogleich die Erfahrung von verstärkter Sinnlosigkeit, von Widersinn.

Dies verschärft sich noch einmal, wenn Gott ins Spiel kommt. Denn für Menschen, die an ihn glauben, spielt Gott eine wichtige Rolle bei der Frage nach Sinn im Leben - und im Leiden.

Im Folgenden werden einige grundlegende Aspekte der menschlichen Existenz bedacht, auf die uns die Corona-Krise wieder neu hinweist, insbesondere auf unsere Sterblichkeit; denn im Bewusstwerden solcher Aspekte sehe ich einen Sinn in der Krise. Dafür greife ich Grundthemen der so genannten „Existenziellen Psychotherapie“ von Irvin Yalom auf $(1)^{3}$. Anders als der nichtreligiöse Psychiater und Autor frage ich dazu als Christ nach der sinnstiftenden Relevanz des Glaubens an Gott (2). Mag dieser Glauben zunächst unserer Existenz Sinn verleihen, so wird er zugleich durch die Erfahrung sinnlosen Leidens in Frage gestellt (3). Abschließend befasse ich mich damit, wie man als gläubiger Christ mit der existentiellen Spannung von Sinn und Sinnlosigkeit umgehen kann - auch in der Corona-Krise (4), nämlich mit einer „Hoffnung wider alle Hoffnung“ (Röm 4,18), die zum Einsatz für das Machbare und zum Sich-Einlassen auf das Unverfügbare ermutigt.

3 Siehe Yalom, Existenzielle Psychotherapie. 


\section{Die Schmerzen der Krise und der sterbliche Mensch}

Die Leiden an der Pandemie sind vielgestaltig, schließlich hat die Krise neben physischen auch psychische, soziale und existentielle, ökonomische und ökologische Auswirkungen. Natürlich weiß jeder, dem schon mal etwas wehgetan hat: mitunter haben Schmerzen ihr Gutes; denn sie signalisieren uns, dass etwas nicht in Ordnung ist, und sie motivieren uns, etwas zu verändern - Fehler zu korrigieren oder uns neu auf veränderte Situationen einzustellen. So ist man gut beraten, mit Zahnschmerzen zum Zahnarzt zu gehen, weniger Süßes zu essen und die Zahnpflege zu verbessern. Durch schmerzliche Prozesse hindurch entwickeln sich Menschen weiter, kommen Gesellschaften voran. Doch scheinen die Folgen der CoronaKrise vielen zu weh zu tun, als dass sie dadurch gerechtfertigt wären.

Ich möchte auf einen tiefer reichenden Sinngehalt des Schmerzes schauen: Krankheit und Leid führen uns unsere Verwundbarkeit vor Augen, und zwar eine Verwundbarkeit, die unausweichlich zu unserer Existenz als Menschen gehört. Wer ernsthaft erkrankt, wird schmerzhaft daran erinnert, dass er sterblich ist - und erinnert andere daran. Während wir im Alltag so leben, als ob wir unsterblich wären, holt uns das lebensgefährdende Virus wie jede schwere Krankheit auf den Boden der existentiellen Tatsachen zurück: die große Aufmerksamkeit für Sterberaten im Zusammenhang mit Covid-19 belegt das. Die Angst vor dem eigenen Sterben wie vor dem Tod Nahestehender dürfte ebenso wie die Angst davor, den Tod anderer zu verschulden, eine große Rolle bei der Akzeptanz von freiheitsbeschränkenden Maßnahmen gespielt haben; umgekehrt wird vielerorts umso ungeduldiger auf Lockerungen gedrängt, je stärker die Todesgefahr gebannt scheint.

Ist es sinnvoll, sich den eigenen Tod bewusst zu machen? Schon die Bibel rät: „Lehre uns bedenken, dass wir sterben müssen, auf dass wir klug werden." (Ps 90,12) Für Irvin Yalom ist das Bewusstsein um die eigene Sterblichkeit von zentraler Bedeutung für das Selbstverständnis und Weltverhältnis des Menschen ${ }^{4}$. Eine oft nicht bewusste und bedachte Angst vor dem Tod, so seine These, spielt mehr in viele Lebenserfahrungen und -probleme hinein, als wir meinen. Krisen wie die Pandemie lenken unseren Blick darauf; das gefährliche Corona-Virus versperrt den Fluchtweg in Verdrängung und Vermeidung.

Zusammen mit dem Tod erörtert Yalom in seiner existentiellen Psychotherapie noch drei weitere Grundkonstanten menschlichen Daseins, die

4 Vgl. Yalom, In die Sonne schauen; Yalom, Existenzielle Psychotherapie, 45-95. 
uns durch Krisen wie die gegenwärtige schmerzlich bewusst werden: Freiheit, Isolation und Sinnlosigkeit ${ }^{5}$. Diese vier Phänomene führen den Menschen in Spannungen, die es zu gestalten gelte.

So steht der Tod in Spannung zu unserer Sehnsucht nach Leben und Lebendigkeit, das drohende Nicht-mehr-sein in Spannung zu unserem Streben nach Ganz-Sein (Heidegger).

Mit „Freiheit" meint Yalom das Fehlen einer Orientierung gebenden Struktur für unser Wollen und Handeln ${ }^{6}$. Frei von Vorgaben müsse und könne der Mensch aus sich heraus sein Leben verantworten, in Spannung zu seinem Wunsch nach einer bergenden guten Ordnung. In der gegenwärtigen Corona-Krise zeigt sich das etwa in der Unsicherheit, an welchen Werten Maßnahmen zur Eindämmung des Virus auszurichten seien: Was gilt es mehr zu schützen - die leibliche Gesundheit, das Leben als solches? Oder die freie Selbstbestimmung auf der Suche nach persönlicher Lebensqualität? Was zählt die Würde des Einzelnen, was bedeutet gesellschaftliche Solidarität?

Mit „Isolation“ bezeichnet Yalom das existentielle Alleinsein des Menschen in Spannung zu seinem Wunsch, Teil eines größeren Ganzen zu sein, mit anderen zu verschmelzen ${ }^{7}$. Nur radikale Akzeptanz einer letzten Einsamkeit befähige den Menschen, gute Gemeinschaft mit anderen zu suchen und zu erleben. In Zeiten von Corona kommt hier einem sofort die isolierende Wirkung des Virus und seine Bekämpfung durch Kontaktverbote in den Sinn, die bis hin zu einsamem Sterben - und Trauern - geführt haben.

Als vierte Grundgegebenheit des Lebens nennt Yalom die Sinnlosigkeit, d. h., das Fehlen eines umfassenden Sinnes für unser Dasein, das in Spannung steht zu unserer Ausrichtung auf Sinn und Bedeutung ${ }^{8}$. Yalom empfiehlt mit dieser Spannung zu leben, indem man die Frage nach dem Sinn im Großen fallenlässt und stattdessen durch praktisches Tun Sinn im Kleinen stiftet. Sich diesen Grundgegebenheiten zu stellen und konstruktiv mit ihnen umzugehen, mache die Größe des Menschen aus, so Yalom. Für ihn ist diese „Auseinandersetzung mit Gegebenheiten der menschlichen Existenz schmerzhaft, aber letztlich heilsam." ${ }^{\circ 9}$

5 Vgl. Yalom, Existenzielle Psychotherapie, 20-22. Zusammen bilden sie die vier Grundgegebenheiten (ultimate concerns), um die herum Yalom seine Psychotherapie entwickelt.

6 Vgl. Yalom, Existenzielle Psychotherapie, 333-408.

7 Vgl. Yalom, Existenzielle Psychotherapie, 411-455, insbes. 455.

8 Vgl. Yalom, Existenzielle Psychotherapie, 485-558, insbes. 556f.

9 Yalom, Existenzielle Psychotherapie, 27. 
Ein existentieller Sinn in der Corona-Krise könnte also darin bestehen, sich den unausweichlichen Gegebenheiten menschlicher Existenz zu stellen und sie kreativ und stimmig in ein Leben angesichts des Todes zu integrieren. Macht hierfür der Glaube an Gott einen Unterschied?

\section{Menschliche Sinnsuche und göttliche Sinngebung}

Irvin Yalom glaubt nicht an Gott; für ihn ist mit dem Tod alles vorbei ${ }^{10}$. Zeit seines Lebens könne der Mensch kreativ mit den existentiellen Spannungen leben, ohne sie vermessen auflösen zu wollen, aber auch ohne an ihnen verzweifeln zu müssen. Christen dagegen glauben an einen guten Gott, den Schöpfer, Begleiter und Vollender der Welt; und an ein „Leben in Fülle“ (vgl. Joh 10,10), mit Überwindung der beschriebenen vierfachen Spannung menschlicher Existenz, auf die uns Krankheiten und Krisen stoßen:

Wer an die Auferstehung Jesu glaubt, lebt von der Hoffnung, dass unser Leben nicht durch den Tod in ein Nichts hinein beendet, sondern von Gott endgültig bewahrt und vollendet wird. Auch für Christen gehört wie bei Yalom die Freiheit zum Wesen des Menschen; nur ist der Mensch als Ebenbild Gottes dazu berufen, sich frei auf ihm angemessene Weise in eine gute Schöpfungsordnung einzubringen, eine Ordnung der Liebe. Es geht um ein Miteinander und Füreinander, das uns zu Menschen macht; denn wir werden erst am Du zum Ich (Buber). Der Glaube daran, dass die Welt nicht durch Zufall entstanden ist, sondern aus Liebe und für „das Spiel der Liebe“ geschaffen wurde, gibt dem Leben einen Sinn, für den es sich zu leben und auch zu sterben lohnt. Darum reicht Jesu Hauptgebot der dreifachen Liebe als Lebensmaxime aus: „Liebe Gott und liebe Deinen Nächsten wie dich [bzw. und dich] selbst.“

Leid, Schmerz und Tod lassen den Menschen spüren, dass die Welt seine Sehnsucht nach bleibender Liebe nicht stillen kann, sondern dass er vielmehr darauf angewiesen ist, eine Erfüllung von woanders her zu erhoffen. Existentielle Krisen stellen uns neu vor die Entscheidung, ob wir weiterhin „an die Liebe glauben“ wollen (bzw. können?). Zu den Tücken des Schmerzes gehört jedoch unter anderem, dass er das Gefühl der Verbundenheit mit anderen, mit anderem attackiert: wer krank ist, kreist stark um sich und sein Kranksein. Diese Fixierung auf die eigene bedrohliche Situation ist auch in Zeiten von Corona zu beobachten - das gilt für Einzelne

10 Vgl. z. B. Yalom, In die Sonne schauen, $193 \mathrm{f}$. 
wie für Gruppen bis hin zu gesellschaftlichen Milieus oder Nationen. Welche Größe zeigen dagegen Menschen, die trotz ihres Leidens sich nicht auf sich selbst konzentrieren, sondern sich auf andere einlassen, an der Liebe festhalten - und an einer Hoffnung jenseits ihrer Möglichkeiten, trotz allem.

\section{Sinn durch Gott und die Frage nach dem Warum des Widersinns}

Der Glaube an Gott enthält eine Hoffnung für die existentielle Sehnsucht des Menschen nach Leben angesichts des Todes, nach Heimat und Ordnung, nach Teilhabe und Liebe, nach umfassendem Sinn; so weit, so gut. Doch warum all das schmerzende Leid?

So fragen Gläubige und Skeptiker auch in Zeiten von Corona, wie schlimme Übel zu einem guten Gott passen. Und wenn wir sie auch hier nicht lösen können, so lassen sich immerhin unangemessene Antworten als unter unserer - und Gottes - Würde ausschließen. Einige Erklärungen, die mit Gott operieren, gehen darüber hinweg, wie übel manches Leid ist:

Ein erster religiöser Erklärungsversuch für die Pandemie lautet: „Gott hat das Corona-Virus geschickt!“ Wer das behauptet, sieht im Virus vielleicht Gottes Strafe für menschliche Sünden - begangen an Gott, an den Mitmenschen, an der Natur. Ich hoffe, ich muss hier nicht näher ausführen, wie sehr diese Vorstellung von Gott und seiner Liebe (?) die vielen schuldlosen Opfer der Pandemie zusätzlich in ihrer Würde verletzt, zumal auch diese Naturkatastrophe wie viele vor ihr insbesondere Arme und Schwache trifft! Es gibt aber auch noch andere Wege, das Leiden am Virus als gottgewollt $\mathrm{zu}$ interpretieren: Vielleicht will Gott damit unsere Menschlichkeit prüfen? Oder gibt er uns das Virus als eine Aufgabe, an der wir wachsen und uns weiter entwickeln sollen? Gegen solche religiöse Sinnsuche ist festzuhalten: Für die Annahme, ein guter Gott könne es gutheißen, ist das virusbedingte Leid zu schrecklich. Ich habe viel Respekt davor, wenn Leidende - meist im Nachhinein - ihr Leiden für sich als sinnvoll deuten („Gut, dass es so gekommen ist!“); doch das darf man nicht anderen vorschreiben! Es muss möglich bleiben, widerfahrenes Leid als sinnloses Übel abzulehnen.

Die leidvollen Auswirkungen des Virus sind nicht gut, sondern von Übel. Wenn Gott gut ist, kann er nicht wollen, was nicht gut ist. Und was er nicht will, das tut er auch nicht. Also will Gott das Übel der Pandemie nicht, und er bewirkt es auch nicht. Er ist allmächtig und allwissend, aber nicht allwirksam. Schon die Bibel erzählt viele schlimme Dinge, die gegen 
Gottes Willen auf der Erde passieren. Zugleich beschreibt sie die Welt als Gottes gute Schöpfung. Wie geht das zusammen?

Eine erste gedankliche Annäherung: Das Übel hat keine eigenständige "Seinsqualität“", sondern ist vielmehr ein - schmerzlicher - Mangel an Gutem, ist dessen Pervertierung - so wie Krebs einen (guten) Organismus befällt, mit seinem Wuchern als entartetem Wachstum. So ist Gott zwar nicht der Schöpfer des Übels, doch muss er sich fragen lassen, wozu er den realen Mangel an Gutem, der so viel Leid mit sich bringt, zulässt.

Schließlich folgt aus der Allmacht logisch, dass Gott das Virus verhindern oder vernichten könnte. Müsste man nicht beseitigen, was man nicht will, wenn man die Macht dazu hat? Eigentlich schon - es sei denn, man hätte hinreichend gute Gründe, etwas zuzulassen bzw. in Kauf zu nehmen, obwohl man es nicht will (so wie z. B. Eltern aus pädagogischen Gründen Dinge bei ihren Kindern laufen lassen, die sie missbilligen und beseitigen könnten - doch das kann auch in Verantwortungslosigkeit umschlagen ...).

Eine Antwort auf die Frage nach diesen Gründen darf in Anbetracht der Leidenden nicht das Übel rechtfertigen, sondern allein dessen Zulassung. Der bislang beste Vorschlag für den gesuchten Wert ist für mich die Freiheit des Menschen ${ }^{11}$; weil ich jedoch nicht sehen kann, dass Gott dafür Naturkatastrophen wie die Corona-Pandemie in Kauf nehmen muss ${ }^{12}$, räume ich ein: Ich habe keine positive Antwort auf die Frage, wozu Gott Übel zulässt! Es kann und muss eine Lösung geben, aber ob wir sie unter irdischen Bedingungen finden oder bekommen, ist angesichts jahrhundertelanger erfolgloser Suche fraglich.

Ohne Antwort bleibt der Glaube an Gott angesichts sinnlosen Leidens erschütterbar. Auch von Jesus ist ein Verzweiflungsruf am Kreuz überliefert: „Mein Gott, mein Gott, warum hast Du mich verlassen!“ (Mk 15,34) ${ }^{13}$ Im Anschluss an so eine Erfahrung hat der Mensch mehrere Möglichkeiten (doch stehen sie wohl nicht einfach zur freien Auswahl): den Glauben an Gott enttäuscht aufgeben, Gott flehentlich anrufen oder sich ihm im Letzten anvertrauen ${ }^{14}$; natürlich gibt es in der Realität Zwischen- und auch Mischformen.

11 Vgl. z. B. Kreiner, Gott im Leid, insbes. 321-391.

12 Für eine Kritik an der so genannten Free Will Defense siehe Splett, Freiheit zum Guten ohne Freiheit zum Bösen - undenkbar?

13 Das Ausrufungszeichen erscheint mir angemessener - Jesus fragt nicht, er klagt.

14 Vgl. dazu ein anderes Wort Jesu am Kreuz: „Vater, in Deine Hände empfehle ich meinen Geist." (Lk 23,46). 
Doch ist das Festhalten am Glauben an Gott ohne Erklärung für sinnloses Leiden nicht töricht? - Gegenfrage: Lässt sich das Übel in der Welt ohne Gott wirklich einfacher erklären? Dazu hier nur ein Gedanke ${ }^{15}$ : Wenn der Protest von Leidenden gegen ihr unschuldiges sinnloses Leiden sinnvoll sein soll, dann setzt dies die Idee einer guten sinnvollen Ordnung voraus, auf die sich der Protestierende berufen kann. In einer zufällig entstandenen Natur ist alles gleich-gültig, Tsunamis wie Viren machen keine Unterschiede. Mit welchem Recht also dürften wir fordern, dass es gerecht und sinnvoll zugehen müsse? Und zugleich macht genau dies die Würde von Opfern aus: gegen Unrecht und Sinnlosigkeit zu protestieren und darauf hinzuweisen, es sollte anders sein! Doch das Fehlen von Sinn kann eigentlich nicht sinnvoll beklagt werden ohne die reale Möglichkeit einer sinnvollen Ordnung - und die braucht einen Sinnstifter, der nicht nur als ursprünglicher Schöpfer, sondern auch als bleibender Garant von Sinn zu denken ist: Gott. Wer Unrecht anprangert, setzt auf Gerechtigkeit. Die Klage gegen Widersinn setzt Sinn voraus. Der Glaube an Gott beantwortet nicht die Frage nach dem Woher und Wozu des Übels, doch bietet er einen Rahmen, in dem sie sinnvoll gestellt werden kann. Und er bietet die Aussicht auf Antwort. Das rechtfertigt nicht den Schmerz des Leides, der durch das Ausbleiben einer Antwort sogar noch gesteigert wird. Doch Gott bleibt im Spiel, als Angeklagter - und zugleich als Grund für die Hoffnung, dass einmal alles gut wird, dass Gott „alle Tränen abwischen wird“. (Offb 21,4)

\section{Die Bedeutung eines Halts in Gott für Haltung und Verbalten in} (Sinn-)Krisen

Krankheiten und Krisen stoßen uns auf Grundfragen des Lebens, der Glaube bietet Sinnperspektiven, zugleich stellt sinnwidriges Leiden diesen Glauben in Frage - wobei sinnvolles Aufbegehren auf der Annahme von Ordnung statt Chaos bzw. von Sinn statt Gleichgültigkeit beruht. Auf diesem Hintergrund seien einige Konsequenzen für einen gläubigen Umgang mit der Corona-Krise skizziert.

Der Glaube an die Überlegenheit von Leben und Liebe über den Tod befreit dazu, Sterben und Tod in den Blick zu nehmen und anderen beizustehen, die davon betroffen sind. Der Glaube an eine gute Ordnung ermu-

15 Wichtige Impulse dazu verdanke ich meinem Vater Jörg Splett, u.a. in Splett, Denken vor Gott, 207-255. 
tigt zum persönlichen wie solidarischen Kampf gegen Not und Leid. Die Hoffnung auf Gott erleichtert mitunter (beileibe nicht immer) auszuhalten, was unsere Macht übersteigt; sie kann erleichtern, Sinnwidrigem zu begegnen, mit „Widerstand und Ergebung“ (Bonhoeffer) - denn statt eines abstrakten Schicksals hat der Glaubende ein konkretes Gegenüber für sein Bitten und Klagen, aber auch für Lob und Dank: Gott. In Situationen von Verzweiflung und Einsamkeit dürfen Gläubige darauf bauen, niemals alleine zu sein, weil Gott immer da ist; wenn wir vieles nicht verstehen, dann ist da wenigstens einer, der alles versteht...

Wer an Gott glaubt, weiß nicht besser Bescheid, wie gegen das Virus vorzugehen ist. Mit Gott hat man es nicht unbedingt leichter in Krisen, doch man hat eine Stärke: „Denn Gott hat uns nicht einen Geist der Verzagtheit gegeben, sondern den Geist der Kraft, der Liebe und der Besonnenheit.“ (2 Tim 1,7) Auch Gläubige stehen in der existentiellen Spannung von Leben und Tod, von Sinn und Sinnlosigkeit, von Ordnung und Freiheit, von Verbundenheit und Alleinsein. Ohne das Dunkle zu verneinen oder zu verdrängen, bleiben sie für das Helle empfänglich. Zum Glauben gehört die Hoffnung, dass Leben, Liebe und Sinn das letzte Wort haben werden und nicht Tod, Lieb- und Sinnlosigkeit. Und das ist nicht nur eine Perspektive für irgendwann - und sei es in einem Jenseits -, sondern das kann uns hier und jetzt schon froh und auch gelassen machen (auch wenn uns nicht immer fröhlich zumute ist). Darum bleibt gerade in Krisenzeiten die Freude als eine christliche Grundhaltung dem Leben gegenüber wichtig. Es gibt neben dem Leidvollen auch viel Gutes, über das wir uns freuen dürfen; und diese Freude sollten wir auch teilen.

Was also tun in Krisenzeiten wie diesen? Christen sei das benediktinische „Bete und arbeite“ ans Herz gelegt, und das mit Martin Luther: „Bete, als ob alles Arbeiten nichts nützt; und arbeite, als ob alles Beten nichts nützt." Dazu abschließend ein bekanntes Gebet von Reinhold Niebuhr:

„Gott, gib mir den Mut zu ändern, was ich ändern kann; die Gelassenheit hinzunehmen, was ich nicht ändern kann; und die Weisheit, das eine vom anderen zu unterscheiden." 


\section{Literatur}

Frankl, Viktor: Der Mensch auf der Suche nach Sinn. Zur Rehumanisierung der Psychotherapie, Freiburg: Herder 1978.

Kreiner, Armin: Gott im Leid. Zur Stichhaltigkeit der Theodizee-Argumente, Freiburg: Herder 1997.

Splett, Jörg: Gotteserfahrung im Denken. Zur philosophischen Rechtfertigung des Redens von Gott, München: Alber ${ }^{4} 1995$.

Splett, Martin: Freiheit zum Guten ohne Freiheit zum Bösen - undenkbar? Weshalb die menschliche Willensfreiheit nicht das Theodizeeproblem löst, in: Ethik und Sozialwissenschaften 12 (2001) 205-207.

Yalom, Irvin: Existenzielle Psychotherapie, Bergisch-Gladbach: EHP-Verlag ${ }^{5} 2010$.

Yalom, Irvin: In die Sonne schauen. Wie man die Angst vor dem Tod überwindet, München: btb Verlag ${ }^{11} 2010$. 